\title{
ECOS DE LA DICTADURA: PINOCHET EN LAS NOVELAS GRÁFICAS DE CIENCIA FICCIÓN CHILENAS $^{\top}$
}

\section{ECHOES FROM MILITARY DICTATORSHIP: PINOCHET IN CHILEAN SCIENCE FICTION GRAPHIC NOVELS}

\section{Guillermo González Hernández*}

\author{
Rec.: 31-03-2021. Acept.: 25-05-2021. Publ.: 30-06-2021
}

DOI: http://doi.org/10.29035/ucmaule.60.11

\section{RESUMEN}

Este artículo analiza tres novelas gráficas chilenas que utilizan la retórica y la estética de ciencia ficción para constituir fabulaciones que se desarrollan con una mirada hacia la dictadura chilena y a la figura de Augusto Pinochet. La revisión de estas obras permite identificar la forma en la que el personaje del dictador es configurado tanto desde la narrativa textual como desde una perspectiva visual mediante el uso de las ilustraciones, conjugando un discurso multimodal que se alimenta de la memoria, la historia y la ciencia ficción, dando vida a un Pinochet personaje.

Palabras clave: Memoria histórica, ciencia ficción, novelas gráficas, Pinochet, multimodalidad.

1 Este artículo fue posible gracias al aporte de Agencia Nacional de Investigación y Desarrollo/ Formación de Capital Humano Avanzado/ 21200313 Beca Doctorado Nacional 2020.

\footnotetext{
* Pontificia Universidad Católica de Valparaíso, guillermo.gonzalez.h@mail.pucv.cl
} 


\section{ABSTRACT}

This paper analyzes three Chilean graphic novels that use science fiction rhetoric and aesthetics to constitute fables that are developed with a look at the Chilean dictatorship and on the figure of Augusto Pinochet. The review of these novels allows to identify the way in which the character of the dictator is configured both from the textual narrative and from a visual perspective through the use of illustrations, combining a multimodal discourse that feeds from memory, history and science fiction, giving life to a character Pinochet.

Key words: Historical memory, science fiction, graphic novels, Pinochet, multimodality.

\section{INTRODUCCIÓN}

Pensar el régimen militar a casi treinta años de su término no es una tarea fácil, especialmente para alguien que no vivió en carne propia los años de dictadura y que la conoce únicamente a través de testimonios, memorias y evocaciones que, siendo tan descarnadas como lo son, solo acercan a las generaciones posdictadura a través de una especie de segunda fuente. Vale decir, jamás será igual generar una visión a través de la propia experiencia que generarla mediante las experiencias de otros. Por lo mismo, la figura del dictador chileno sigue siendo controversial, pues enmarca las tensiones ideológicas e incluso morales que aún se articulan en los discursos políticos, artísticos y culturales en Chile.

En concordancia con lo anterior, Augusto Pinochet y la dictadura que encabezó, siguen siendo una presencia polémica que mantiene tanto detractores como simpatizantes, por lo que resulta relevante observar cómo esta figura se plasma en las distintas ficciones literarias, particularmente en aquellas que asumen una estética de ciencia ficción ${ }^{2}$ y que son desarrolladas para un lector que reconoce al personaje, pero que generacionalmente se encuentra desplazado de la dictadura militar. En este sentido, las novelas gráficas de ciencia ficción son un terreno fértil para el despliegue de espacios que tensionen la figura real de Pinochet con la reconfiguración de su identidad e imagen como personaje ficticio, pues, por una parte, desde la propia fabulación de la ciencia ficción se posibilita la exploración de la humanidad, sus sentimientos y sus pro-

2 Entre ellas se pueden encontrar 2010: Chile en llamas (1998) de Darío Oses o Synco (2008) de Jorge Baradit, por señalar un par de ejemplos. 
ducciones, permitiendo situar ciertos aspectos de nuestro mundo en un entorno ajeno a lo que entendemos por realidad, de modo que los supuestos que sustentan a la sociedad son cuestionados, apreciados y comprendidos en relación a las consecuencias que de ellos se pueden desplegar (Muñoz, 2009). Mientras que, por su parte, la narrativa gráfica permite, a través de las imágenes, constituir personajes desde estereotipos ${ }^{3}$ y formas icónicas que los evocan, además de plasmar de manera más comprensible las experiencias que constituyen el entramado existente entre la memoria-historia y la ficcionalización de la misma.

Ambos puntos conforman una fórmula que cohesiona la retórica y estética de la ciencia ficción con el soporte material de la narrativa gráfica, para acercar figuras y procesos de la historia pasada y reciente, proporcionando un espacio que en sí mismo constituye archivo y que funciona en relación a los postulados de Eisner (2017), como un objeto de lectura verbal-visual preferible y natural "para la nueva juventud educada con la televisión, los ordenadores y los videojuegos" (p. 16)

En este sentido, la producción de narrativas gráficas centradas en la dictadura militar chilena, a poco más de treinta años de su término, sin ser del todo imprescindibles, sí se tornan inevitables como recurso retórico para la revisión de los discursos de la memoria oficial o pactada, abriendo un espacio para el desarrollo de memorias colectivas y de discursos corales que emergen desde los nuevos contextos socio-políticos que experimenta Chile en la actualidad, los cuales se arraigan en la mediatización de la cultura de masas.

El presente trabajo, cuyo título es Ecos de la dictadura: Pinochet en las novelas gráficas de ciencia ficción chilena, tiene por objetivo general analizar la construcción y desarrollo de Pinochet como personaje dentro de tres novelas gráficas de ciencia ficción que son: Zombies en La Moneda: jestamos en guerra, señores! (2015), El gran guarén: los archivos perdidos (2016) y 1959: Metahulla 2 (2018). A partir de este objetivo general se han implementado objetivos específicos que se ejecutan transversalmente en cada una de las obras estudiadas. Primero, identificar la forma de caracterización del personaje; segundo, determinar la relación entre el ejercicio memorístico y la configuración del personaje; tercero, demostrar la importancia del vínculo imagen/ texto en la construcción y desarrollo del personaje.

Siguiendo esta lógica, la revisión mimética que se establece entre el personaje y el referente asumirá un carácter de agente dentro de las configuraciones hipotéticas que

3 La RAE (2020) define estereotipo como: “Imagen o idea aceptada comúnmente por un grupo o sociedad con carácter inmutable." 
se le confieren a Pinochet personaje dentro de las novelas gráficas estudiadas. Dicho de otro modo, la articulación entre el Pinochet personaje y el Pinochet referencial será un factor determinante en el modo en el cual se construye y reconstruye esta figura en cada una de las obras.

\section{Historia, memoria y ciencia ficción}

Analizar un personaje vinculado directamente a un referente de por sí es una tarea delicada. Lo es aún más cuando dicho referente posee una carga histórica y simbólica tan alta que se encuentra arraigada en metarrelatos ideológicos, haciendo que lo extratextual sea prácticamente inseparable del contenido literario y que su lectura se encuentre, de cierta manera, condicionada por ello. En consecuencia, las novelas gráficas revisadas se nutren de la relación existente entre memoria, historia y ficción, pues incorporan personajes y acontecimientos que entrelazan las tres dimensiones mencionadas y configuran una fabulación que emerge como disputa entre lo mimético de la configuración de sus personajes y la constitución de invenciones que se distancian de los referentes extratextuales para parafrasear la historiografía que se plantea como telón de fondo. La importancia de revisitar la figura del dictador Pinochet a través de las novelas gráficas de ciencia ficción, radica tanto en la articulación retórica que se hace de él como dispositivo dentro de las narraciones, como en la carga semántica y pragmática que conlleva su construcción como personaje dentro de la extensión cultural de la memoria histórica de Chile. Es importante destacar también que esta relectura y reconfiguración de Pinochet como personaje y la dictadura como un escenario literario, ha traspasado la tradición de los soportes narrativos canónicos en los que se han desarrollado estas temáticas desde el propio periodo dictatorial hasta la fecha. Al respecto, Bernardita Ojeda (2016) apunta que

[...] no cabe duda que todo episodio histórico se puede narrar en múltiples formatos (películas, documentales, libros), y el cómic es uno de los más privilegiados: no solo los dibujos permiten entregar información valiosa desde el punto de vista historiográfico y sociológico, reconstruyendo una época (reflejando vestimentas, lugares, formas de vida, modos y costumbres), también el guion puede aportar con narrar de manera más cercana esa "pequeña historia" que nos remite de lo particular a lo general, que permite observar grandes procesos sociales a partir de una anécdota muy breve o realizados por personas anónimas, sin que necesariamente pase por enfrentar o abordar las grandes figuras de la época. (p. 1) 
Visto de esta manera, las novelas gráficas, al ubicarse entre las fronteras del relato cinematográfico y la narrativa verbal, plantean un campo alternativo de desarrollo de ficcionalizaciones históricas, al mismo tiempo que, precisamente, reubica la mirada de los procesos socio-históricos desde una perspectiva prospectiva vinculada, en este caso, a la estética y retórica de la ciencia ficción.

La relación/tensión entre historia y memoria que presentan las obras sujetas a estudio, es un eco de la amplia atención que ha tenido la construcción de la memoria histórica y que se ha transformado en uno de los tópicos centrales de los distintos estudios e investigaciones tanto en la literatura como en las ciencias sociales en general.

En los últimos años han ido surgiendo, tanto en Argentina como en Chile, narrativas autobiográficas sobre las respectivas dictaduras escritas por hijos de desaparecidos o implicados en la militancia política de los 70 . Esos textos forman parte de un vasto corpus de elaboraciones estéticas aún en pleno desarrollo que, desde diversos ángulos, reflexionan sobre las secuelas de los gobiernos autoritarios, al tiempo que instalan una distancia crítica respecto al proyecto revolucionario de los años 70. (Logie \& Willem, 2015, p. 2)

Esto se debe principalmente a las transformaciones políticas que dieron un giro hacia la recuperación de la memoria dentro de los procesos de democratización de los países latinoamericanos, los cuales entraron en una dinámica del consenso luego del fin de las dictaduras, especialmente en Chile y Argentina (Avelar, 1999). Este modelo consensual al que se refiere Nelly Richard (1998), revisa la relación entre memoria e historia como una articulación entre pasado y olvido, en la que el pasado deviene en memoria y a través de dispositivos, como la literatura, entra en pugna con la problemática intersubjetiva de la "verdad histórica". Este espacio de la memoria e historia, cuando son coincidentes, permite evidenciar una memoria histórica que comprende una revisión biográfica en conjunción con la historiografía oficial. En cambio, cuando entran en tensión, la memoria histórica se difumina y se transforma en una memoria de la historia ${ }^{4}$, es decir, una memoria que pierde su carácter biográfico y entra en el terreno de la memoria de los otros (recuerdos de recuerdos) o en la memoria investigativa que se fundamenta en procesos llevados a cabo por el deseo de "conocer" o "saber".

La formulación de un personaje como Pinochet dentro de la ciencia ficción, articula un ejercicio memorístico que suscita la comprensión de un proceso histórico y político cuyas repercusiones se pueden evidenciar en la actualidad sin encontrarse

4 Ver Ruiz Vargas, José María. ¿De qué hablamos cuando hablamos de 'memoria histórica'? Reflexiones desde la Psicología cognitiva. Entelequia. Revista Interdisciplinar 7. 2008 (53-76). 
necesariamente ligado a la escritura de "los hijos", sino más bien, opera desde y hacia el espacio de los nietos de quienes vivieron la represión de los años setenta. En consecuencia de esto, el uso de la memoria, en el caso de las obras estudiadas, está lejos de ser testimonial o autobiográfico, más bien se reconocen elementos de recuperación historiográfica enmarcada dentro del conocimiento general que se tiene sobre los personajes, espacios y acontecimientos, sumado a una recopilación de información pertinente para darle mayor sustento a las fabulaciones. Así mismo, la memoria (sea histórica o de la historia) se vincula con la retórica de la ciencia ficción para complementar, rebatir o razonar el velo de oficialidad con el que se ha cubierto la historia de Chile en el periodo de posdictadura. Esto no solo desde una "recuperación" del pasado, sino también como una memoria del futuro que proyecta tanto el pasado como el presente hacia su probabilidad.

Gabriel Trujillo (1991) indica que "la ciencia ficción ha utilizado la historia como un recurso narrativo. La historia, debido a esto, se divide en un pasado reinventado y en un futuro controlado." (p. 286). Con esto se podría llegar a entender la ciencia ficción desde dos puntos: primero, como una fabulación contrafactual de los hechos que permite reflexionar y tomar distancia sobre la operatividad del presente, cuestionando lo que creemos saber. El ejemplo más claro de esto es la novela de Phillip K. Dick, El hombre en el castillo, obra en la que se presenta un Estados Unidos gobernado por Japón y la Alemania Nazi, luego de que estos países ganaran la Segunda Guerra Mundial. Esta novela, al ser publicada en 1962, discutía que la sociedad extratextual norteamericana no era muy diferente a la de la obra, de hecho, incluso hoy podemos ver cómo consignas de un patriotismo exacerbado y una tensión racial tienen a este país envuelto en una crisis social, siendo en el papel, el paladín de la democracia. En el caso de las novelas gráficas del presente estudio, este ejercicio es realizado en 1959 Metahulla 2 y en El gran guarén: los archivos perdidos, en las que, como apuntaré más adelante, se modifica el referente historiográfico para generar una ucronía que modifica la relación entre Pinochet y Allende, así como una nueva explicación del golpe de Estado, respectivamente.

Como segundo punto, se podría entender que la ciencia ficción es una Historia del futuro. Esta historia con mayúscula daría cuenta de una historiografía probable del futuro, algo similar a lo realizado por futurólogos, mediante lo que se pretende anticipar lo que ocurrirá en los tiempos venideros. Tanto desde la construcción de un futuro probable como de un pasado probable, la historia se fragmenta y llena sus vacíos con estas creaciones que traen lo desconocido hacia nosotros. En su retórica, entonces, la ciencia ficción le permite a la historia interrogarse y complementarse, puesto que se 
cimienta desde un carácter hipotético que otros géneros no llegan a poner en práctica totalmente. Las preguntas ¿qué pasaría si...? o ¿qué hubiese pasado si...? no solo permiten configurar nuevos escenarios desconocidos, sino también cuestionarse lo conocido, lo que pareciera estar escrito en piedra.

En relación con lo anterior, en Zombies en La Moneda jestamos en guerra, señores! la aplicación de la ciencia ficción es profundamente estática y solo se constituye como un soporte para establecer una sátira sobre la realidad chilena desde el nuevo milenio en adelante. En este caso, la memoria-historia reciente tiene un pequeño cariz de memoria histórica, pero se encuentra más cargada hacia la reproductibilidad de los discursos mediatizados y masificados a través de la televisión o internet. Con esta memoria-historia proveniente de la masificación comunicacional, se establecen los parámetros para crear un país asediado por los zombies (alegoría explícita del sujeto neoliberal, consumidor y consumista) que en algún punto son controlados por Pinochet.

Tomando las palabras de De Certeau (1995), quien señala que la ficción es el "otro" reprimido por la historia y que esta crea simulacros (novelas, por ejemplo) en los que se puede evidenciar lo que la historia se ha negado a ser, podemos entender que la historia se interesa en lo verdadero, mientras que la ficción estaría interesada en lo real, de modo que esta última abriría el campo de lo posible. En efecto, Hayden White (2010) se refiere a lo verdadero como algo posible de identificar a través del registro documental, pero que proporciona un aspecto muy pequeño de la realidad. "Sin embargo, el resto de lo real [...] consistiría en todo lo que puede ser verazmente dicho acerca de su efectividad más todo lo que puede ser verazmente dicho acerca de lo que podría probablemente ser" (p. 169). Por ello, el aporte de la ciencia ficción no es necesariamente imaginar cómo serían las cosas de determinada forma, sino más bien ayudar a complementar los vacíos de significado de la historia que no son más que vacíos de realidad.

\section{La identidad del personaje}

Paul Ricoeur (1996) enfrentaba la dicotomía entre el personaje del relato y la acción de la trama para reflexionar sobre la construcción de la identidad narrativa. Ahora bien, estas reflexiones apuntaban a la forma en la que la identidad del personaje se desarrolla dentro de una autoficción, abordando estas temáticas para el estudio del relato en cuanto este es efectuado por un autor-narrador-personaje que construye su propia identidad. No obstante, las nociones de ipsidad y mismidad que plantea, desde esta lectura, también serían aplicables para la creación y desarrollo de la identidad 
narrativa del otro, sobre todo cuando ese otro posee una carga referencial tan alta como en este caso.

Ricoeur le atribuye una importancia fundamental al relato como determinante absoluto de la identidad del personaje: "El relato construye la identidad del personaje, que podemos llamar su identidad narrativa, al construir la de la historia narrada. Es la identidad de la historia la que hace la identidad del personaje." (Ricoeur, 2006, p. 147). Las obras analizadas obedecen a esta premisa, por tanto, independiente que se trate de la caracterización de un personaje desde la visión del "otro", es este otro quien le otorga parte de sus propias concepciones a partir de la trama que encierra al personaje.

Pinochet, como personaje, queda velado por la propia visión de los autores quienes, en este caso, toman dos caminos para la configuración tanto de su imagen como de su carácter. En Zombies en la Moneda jestamos en guerra, señores!, el componente mimético, entendido como el punto en que ficción e Historia se entrecruzan, es el pilar de la caracterización del personaje, pues se presenta construido desde la mismidad histórica, razón por la cual el personaje opera como "una solución quizás demasiado efectiva para el problema de los Zombies" (fig. 1).

Figura 1. Viñeta Zombies en La Moneda jestamos en guerra, señores!

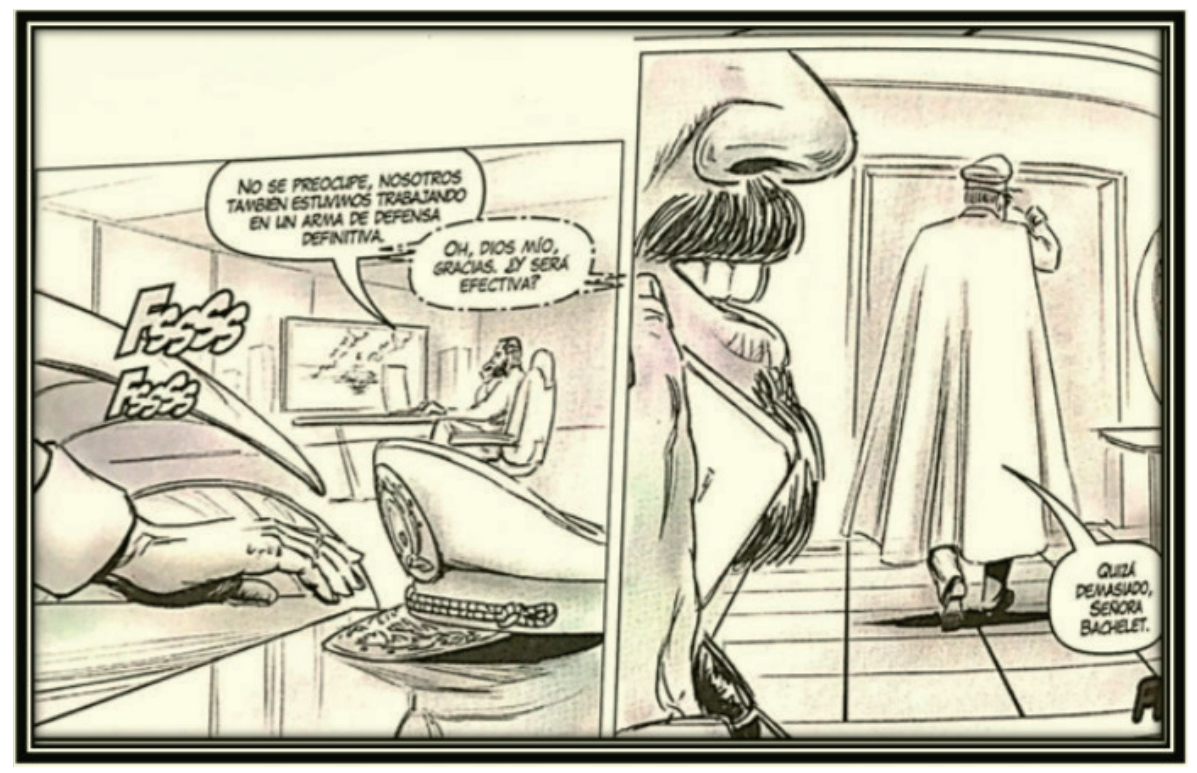

Fuente: Equipo ZELM (2015) 
Cabe destacar que esta novela gráfica está hecha bajo la idea de crear un apocalipsis zombie en Chile y, con ello, permite destacar el componente de ciencia ficción al hipotetizar sobre lo que ocurriría si este desastre se diera en el territorio nacional. De este modo, emplea figuras públicas como políticos, actores, cantantes y personajes de la farándula criolla para situarlos como agentes del desarrollo del relato. En este sentido, Pinochet es un personaje secundario que se termina alzando como un antagonista mayor, al utilizar a los monstruos como forma de opresión y al revelarse a sí mismo como la encarnación del mal. De forma similar ocurre en El gran guarén, pues la relación mimética entre el personaje ficcional y el histórico sigue siendo estrecha tanto en la representación de la imagen como en el discurso. En relación con esto, los elementos que configuran al personaje Pinochet son prácticamente duplicados del Pinochet referente, por ejemplo la expresión "acá no se mueve una hoja sin que yo lo sepa" o la idea de que "es un soldado leal" bajo los ojos de Allende (fig. 2).

Figura 2. El gran guarén: los archivos perdidos.

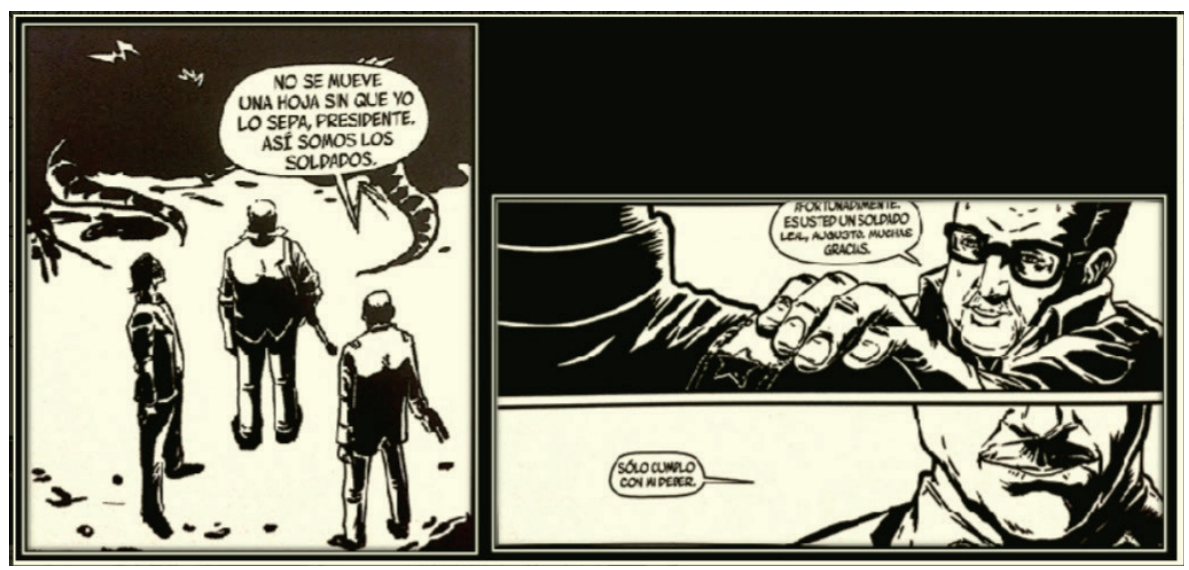

Fuente: Álvarez et. al. (2016)

Ambos relatos, Zombies en La Moneda jestamos en guerra, señores; y El gran guarén: los archivos perdidos, configuran al personaje como un elemento secundario que permite que la trama se desarrolle. En el caso de la primera obra, Pinochet es situado como una especie de pharmakon que es empleado para solucionar un problema, pero termina siendo el propulsor de una catástrofe mayor. Por su parte, la segunda obra gráfica referida, es menos explícita en cuanto a la construcción de Pinochet como el gestor de la crisis, sin embargo, se puede inferir que, si bien no es quien crea a lo guarenes mutantes, detiene su exterminio al realizar el Golpe de Estado en 1973. 
En cuanto a 1959: Metahulla 2, el carácter mimético del personaje se difumina y termina configurándose como una contrapartida del Pinochet referente. Esto se debe a que la obra plantea la noción de un multiverso ${ }^{5}$ cuántico, en el cual operan los mismos personajes, pero con circunstancias diferentes que los llevan a actuar y conformar su carácter de modos distintos. Dicho de otro modo, la construcción de los personajes se hace desde la ipseidad de los mismos, ya que en este universo (7959: Metahulla 2), Pinochet y Allende son amigos, mientras que en otro (en el que guarda relación con la historiografía extratextual) Pinochet quiere asesinar a Allende (fig 3).

Figura 3. Viñeta de 7959: Metahulla 2

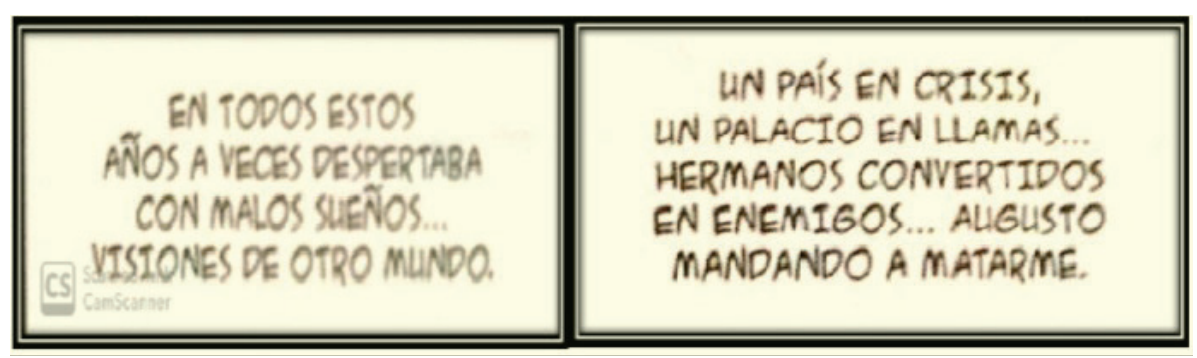

Fuente: Ortega y Dániel (2018)

\section{El desarrollo del personaje}

En cuanto al desarrollo del personaje a lo largo de cada una de las novelas gráficas, debemos entender que este está sujeto a dos elementos que se imbrican dentro de las obras: por un lado, la perspectiva del narrador y, por el otro, la diégesis misma.

[...] la cuestión de la voz -esto es, quién habla- que define el tipo de relaciones que se establece entre la narración y la historia o el relato, que afecta directamente al "estatuto caracterizador», implica, entre otra serie de aspectos concernientes a la instancia narrativa, a la posición del narrador con respecto a la historia que cuenta. De lo que se desprende, es evidente, que, según el tipo de narrador en cuestión, las caracterizaciones de los personajes oscilarán entre una serie de niveles que irán desde el distanciamiento hasta la caracterización parcial, mediatizada o interesada. (Álamo, 2006, p. 199).

5 La noción misma de la multiplicidad de universos ha sido explorada desde el siglo XVI con la Teoría de los muchos mundos de Giordano Bruno, pasando por la Interpretación de los mundos múltiples de Hugh Everett (1954) hasta los estudios más recientes de Edward Witten, siempre bajo la idea de que "en un multiverso [...] cualquier acontecimiento que pueda ocurrir sucederá un número infinito de veces [considerando] que tales universos coexisten en un "espacio de probabilidades», más que en un único espacio real." (Nomura, 2017, p. 16). 
De este modo, Pinochet personaje se construirá como tal desde una voz narrativa que, junto a las acciones de los personajes que conformarán el relato y la relación de estos con la trama, configura los elementos formales que le dan el carácter central al personaje. Sin embargo, dentro de las novelas gráficas existe una multiplicidad de voces narrativas, las cuales dependen de quién es el protagonista de cada episodio, de qué relación tienen los episodios entre sí y, lo más importante, qué conforma cada una de esas voces dentro del entramado de la diégesis. La obra Zombies en La Moneda jestamos en guerra, señores! cuenta con ocho guionistas y trece dibujantes que han dividido el relato en once partes, siendo la estudiada la parte final de una saga aún mayor. Esta novela cierra el apocalipsis zombie desatado en Chile con el retorno de Pinochet, quien es revivido para controlar a los muertos vivientes, pues ninguna de las soluciones anteriores ha sido efectiva.

La novela no solo utiliza a Pinochet como personaje, en ella podemos ver a MicheIle Bachelet, Sebastián Piñera, Alexis Sánchez, Tomás González, entre otros. Todos estos personajes conforman una especie de ejército que, en una primera instancia, luchan contra los zombies y luego intentan eliminar a Pinochet. El relato mezcla la acción, la comedia y el gore, para finalizar con un palacio de La Moneda que ha sido destruido y con un país unido después de la catástrofe. En este escenario, Pinochet personaje es caracterizado y desarrollado de forma indirecta y diseminada a través de las imágenes y diálogos que tanto él como otros personajes realizan en torno a su figura. Se evidencia un personaje malévolo con complejo de superioridad que establece su poder mediante el terror y la fuerza. Se establece, además, como un personaje demoniaco que representa la encarnación del mal y que se mueve dentro del terreno del ocultismo y la magia negra.

Todas estas características se van desarrollando de forma separada en cada uno de los episodios, conformando de manera global un personaje antagónico frente a las fuerzas protagónicas de la novela.

Lo que me parece impresentable es que pensaran que me iban a controlar tan fácil. Si querían un títere, deberían haberse quedado con ese cabro Piraña [...] Ustedes querían una figura que atrajera al ejército, a los empresarios, a las masas ignorantes. Yo soy más que eso señores. Yo soy Augusto Pinochet, mierda [...] Ejecutar orden $666^{6}$. (Equipo ZELM, 2015, p. 96).

6 Referencia tanto al número de la bestia como a la orden 66 dada por Palpatine a los clones para eliminar a los Jedi en La Venganza de los Sith, lo cual también marca el desplazamiento generacional al hacer un guiño a Star Wars, pero no a la saga de los años 80 , sino a la del nuevo milenio. 
El gran guarén: los archivos perdidos, por su parte, nos presenta al personaje de Pinochet de forma breve, pero fundamental. En una secuencia que no supera las siete viñetas se deja constancia de Pinochet como General del Ejército durante el gobierno de Salvador Allende, de hecho, es este último el que funciona como nexo entre la trama de los guarenes gigantes y la aparición de Pinochet, quien salva la vida de Allende, pero impide el exterminio de los ratones mutantes al realizar el golpe de Estado. Más adelante, en una viñeta ambientada en 1976 se menciona que: "Claro que estamos enterados [de los guarenes]. ¿Usted cree que pasa algo en este país sin que nosotros lo sepamos? Si esos guarenes están ahí es porque el general así lo quiere." (Álvarez et al., 2016, p. 15).

En relación con lo anterior, también podemos evidenciar una caracterización indirecta que no depende fundamentalmente del desarrollo de la trama, sino de las inferencias que pueden ser extraídas tanto de los diálogos como de las imágenes que componen las viñetas. Dicha caracterización se realiza en base al nombre del personaje, pues, tal como lo señala Muñoz Molina,

Mediante el nombre se transmite al recién nacido el alma de su antepasado: el nombre es el núcleo y la cifra de la identidad, y el novelista sabe que si da un nombre equivocado a un personaje le otorgará una identidad falsa que le impedirá existir plenamente [...]. Con algunos nombres pasa como con algunos personajes: que uno los tiene antes de tener la historia, y los guarda y no sabe todavía para qué van a servirle [...] (1993, pp 40-41).

Pinochet, en tanto nombre, viene con una preconfiguración previa y que guarda una connotación dentro de su sustancia. Sin embargo, la forma en la que es tratado como personaje dentro de la novela es la que le otorga el carácter como tal. En El gran guarén: los archivos perdidos no hay un mayor desarrollo del personaje y se apela simplemente a la relación que existe con el sujeto-referente para que el lector infiera sus aspectos básicos como personaje.

Finalmente, en 1959: Metahulla 2 se hace patente una caracterización y desarrollo del personaje de forma directa y en bloque, vale decir, se entregan todas las características del personaje en conjunto, sin la necesidad de distribuir dichas características a lo largo del texto. Es más, esta caracterización asume la forma de una heterocaracterización ${ }^{7}$, pues es a través del relato del personaje de Salvador Allende que conocemos

7 José Valles Calatrava, en su texto Teoría de la narrativa. Una perspectiva sistémica, define la heterocaracterización como la caracterización de un personaje a través de la voz del narrador o de otro personaje. (2008: 169) 
la conformación del carácter del Pinochet personaje, junto con la relación que se establece entre ambos personajes que es lo que le otorga dinamismo a la trama.

La adopción de la voz de Allende como narrador y, por ende, como caracterizador de la figura de Pinochet establece el marco en el cual la trama se desarrollará, ya que desde un comienzo rompe con la carga mimética con los referentes reales y los constituye a partir de la ficción misma, mediante el argumento (que se conoce al final del relato) de que existe una multiplicidad de universos donde existen los mismos personajes, pero que se desenvuelven de manera distinta, la cual se interpreta a partir de la imagen de la viñeta y la cita a Paul Éluard: “Hay otros mundos, pero están en este”.

Las implicancias de esta diferenciación en las formas de caracterizar y desarrollar la figuración del personaje en las distintas obras, radican, primero, en el grado de vinculación que Pinochet personaje tiene con su referente extratextual, puesto que, al aludir a las propias palabras de quien encabezara el golpe de Estado en Chile y utilizar datos relacionados con la historia de la dictadura chilena (como sucede en Zombies en La Moneda jestamos en guerra señores y El gran guarén: los archivos perdidos). una mayor descripción y progresión del personaje en la construcción del propio relato resulta innecesaria producto del historicismo inherente del personaje. No sucede lo mismo en 1959: Metahulla 2, debido al distanciamiento que establece esta obra con la historia extratextual y no utiliza ningún elemento vinculante hacia la persona real. Es por ello que el desarrollo del personaje queda sujeto a una descripción más acabada y a una contextualización que explique las condiciones que adquiere Pinochet dentro de la configuración de la diégesis, dando paso a una complementación de la información a través de la voz de Allende quien, al menos en la imagen, mantiene los mismos elementos que su contraparte en la realidad.

Todo lo anterior se enlaza con una segunda implicancia referida al rol que cumple el personaje de Pinochet dentro de estas novelas gráficas, siendo trazado de manera transversal como un personaje secundario que es fundamental para el avance de las acciones dramáticas que se ejecutan en el eje narrativo de las obras. Si bien en la obra gráfica del Equipo ZELM Pinochet adquiere una mayor importancia al pasar de un rol secundario a un rol antagónico, sigue siendo expuesto como un personaje que, sin ser necesariamente el sujeto principal, es fundamental para la generación del conflicto que da movimiento a las tres novelas. 


\section{Imagen y texto}

Como se indicó anteriormente, existe una alta carga mimética entre los parlamentos que dice Pinochet personaje con las imágenes que los representan, por lo tanto, es necesario revisar la iconicidad existente en dichas imágenes y de esta forma poder establecer comparaciones con el referente. El análisis multimodal cobra sentido en este caso, pues, tal como apunta Sáez Rivera (2011) “por la combinación de lo visual o gráfico y lo escrito, el cómic, historieta o tebeo es uno de los textos multimodales por excelencia, ya que en su configuración se combinan dibujos y el código verbal, vehiculado mediante una serie de recursos caligráficos y tipográficos" (p. 771).

En virtud de lo anterior, las novelas gráficas estudiadas configurarán al Pinochet personaje desde una iconicidad que, según los postulados de Mussetta (2016), viene a reemplazar las concepciones de mímesis. Esto está dado porque, al establecer el código visual como un elemento preponderante en la comprensión de la obra multimodal, las descripciones verbales ya no son las que, de forma exclusiva, van a definir a los personajes, sino que los atributos físicos que presentan las imágenes van a tener un valor igual o mayor en la configuración de las características. Este grado de iconicidad, entendido como un recurso semiótico mediante el que el representante es similar a lo representado (Peirce, 1955), resulta vital en la conformación de Pinochet dentro de Zombies en La Moneda jestamos en guerra, señores! y El gran guarén: los archivos perdidos, puesto que en ellos la representación de este personaje se relaciona con una prefiguración correspondiente al referente. Es decir. Pinochet personaje se asimila al Pinochet extratextual. Esto lo podemos evidenciar en cómo es dibujado el personaje, manteniendo en ambos casos dos elementos icónicos irrenunciables: el uniforme militar y las gafas oscuras.

Sin embargo, en el caso de la narrativa de zombies, también se utiliza una carga simbólica para conformar la imagen del personaje, la cual se relaciona con elementos diabólicos y satánicos. Dicho de otro modo, en algunas viñetas, Pinochet es acompañado por estatuas de demonios y rodeado de oscuridad, para finalmente transformarse en un hibrido entre lo demoniaco y lo humano. 1959: Metahulla 2, por su parte, despoja la imagen de Pinochet de los elementos más "icónicos" de su figura. No aparece con traje militar ni con gafas oscuras, ni siquiera con bigote. Esto denota la separación que se pretende establecer entre el personaje y su referente, dando al desarrollo de la 
historia la posibilidad de vincularlo con Allende a través de una amistad. Con respecto a esto, es importante destacar que, si bien Pinochet no posee un grado tan alto de iconicidad como en las otras obras, Allende conserva todos sus rasgos representativos, lo que nos evidencia una vez más la intención de posicionar a Pinochet desde una ficcionalización que no se alimenta directamente de la historicidad de su referente (fig. 4).

Figura 4. Viñetas

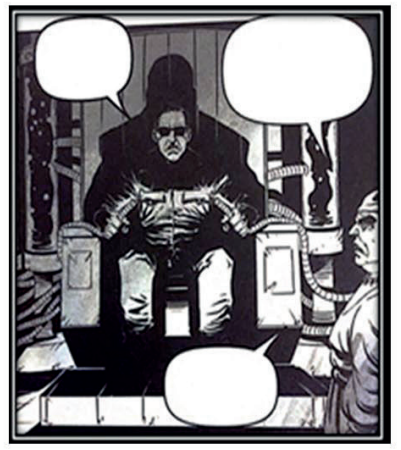

Fuente: Equipo ZELM (2015)

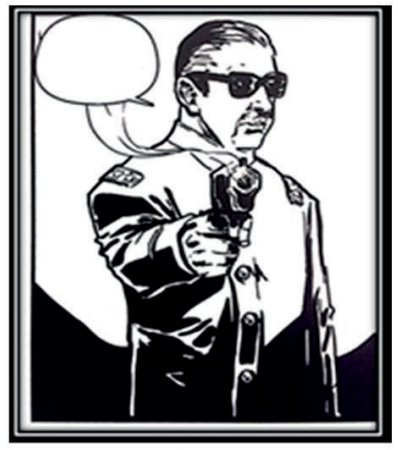

Fuente: Álvarez et al. (2016)

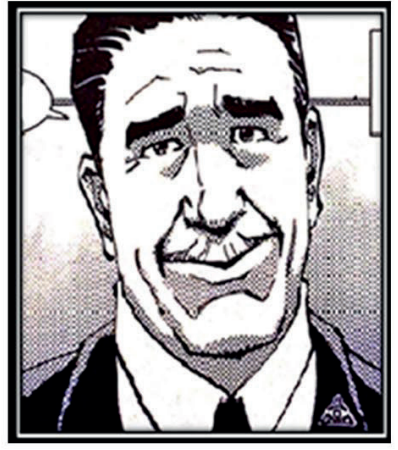

Fuente: Ortega y Daniel (2018)

Es en la relación imagen/texto en la que la ciencia ficción encuentra un valor fundamental al servir como soporte tanto de la fabulación del relato como de la construcción y configuración del personaje. Además, en su conjunto, imagen, texto, historia y ciencia ficción, logran un efecto que se extiende fuera de los márgenes semánticos de las novelas y las transforma en discurso pragmáticos. En otras palabras, la comunión de elementos permite que desde el contenido de las obras emerja una intencionalidad que busca afectar la realidad del lector, tomando la ciencia ficción como el recurso que le da verosimilitud a los relatos, modificando en mayor o menor grado elementos propios de una memoria-histórica nacional para, a través de las ilustraciones y textos, introducir perspectivas que tensionan el pasado, presente y futuro.

En concordancia con lo anterior, sin perjuicio de que imagen y texto promuevan ciertos efectos en el lector, la formulación multimodal propia de las novelas gráficas involucra revisitar el contenido de ellas desde la significancia que adquiere lo escrito y lo visual, ya sea como un único cuerpo o bien como formas separadas, en ese sentido, la complementariedad de la información de ambos registros o la unión iconotextual que exista, también influyen en la manera en que Pinochet personaje es construido en las obras. Por lo mismo, revisar la mayor o menor carga semántica que tiene tanto 
el registro verbal como el visual es indispensable para evidenciar desde que lugar se sostiene el contenido y contexto que envuelven al personaje analizado.

En el caso de Zombies en La Moneda jestamos en guerra, señores!, el peso del contenido del personaje recae en la imagen ilustrada, pues es esta la que le confiere las características más relevantes y sitúa al componente verbal como un complemento de la información visual. La propia resurrección del personaje como la forma en la que se mantiene con vida son descritas en los dibujos, ocurriendo lo mismo en la manera en que es expuesta su cercanía con el oscurantismo y las prácticas satánicas, inclusive el componente de ciencia ficción también se encuentra mayormente dispuesto a través de las imágenes. En esta novela gráfica, lo textual se presenta para dar vida a los parlamentos de los personajes, describir algunas acciones y escenarios, pero es prácticamente nula su funcionalidad en cuanto a generar un argumento más relevante para la construcción del personaje.

En El gran guarén: los archivos perdidos, en cambio, al tener una participación del Pinochet personaje concisa, se produce un acople entre imagen y texto que permite una paridad en la carga semántica que opera en cada uno y que se manifiesta en una caracterización del personaje más integral. Por su parte, 1959: Metahulla 2 toma el camino contrario al de la primera novela gráfica referida, ya que la significancia mayor está puesta en el componente verbal y las imágenes solo funcionan en la medida que el texto las introduce, es decir, la comprensión cabal del personaje de Pinochet solo se alcanza con la lectura y comprensión del texto, debido a que, como se ha indicado antes, la imagen física de dicha figura queda desprovista de las partes icónicas que se le atribuyen al modelo real.

\section{CONCLUSIONES}

La articulación entre historia y ciencia ficción es un fenómeno interesante de explorar, puesto que plantea un diálogo entre pasado, presente y futuro, permitiendo no solo el cuestionamiento del presente, como es usual en las obras del género, sino que, al mismo tiempo, una interrogante sobre lo que se hizo en el pasado y lo que se pretende proyectar hacia lo venidero. En consonancia con lo anterior, las novelas gráficas estudiadas reestructuran las tensiones políticas e ideológicas que sumieron a Chile en la dictadura militar para generar, desde la retórica de la ciencia ficción, relatos que en cuanto a diégesis se alejan del discurso historiográfico, pero que de igual forma lo atraviesan plenamente al desarrollar personajes con una alta carga simbólica-histórica, como es el caso de Pinochet. 
A partir de la revisión de las novelas gráficas que utilizan la retórica de ciencia ficción e involucran la figura del fallecido dictador chileno, se pueden señalar dos conclusiones sobre la configuración del Pinochet personaje, tanto desde la construcción que se hace de él en el relato como de la forma fisiológica que se le da en las distintas ilustraciones. Sin embargo, antes de desarrollar las conclusiones, es primordial precisar que, dentro del moldeamiento que se hace de dicho personaje, el entretejido que forma esta suerte de trialéctica entre memoria-historia-ficción no solo es una propulsora de la elaboración de las novelas gráficas, sino que, además, se posiciona como el centro de las progresiones de las acciones, acontecimientos y fabulaciones que existen dentro de las mencionadas novelas. Es por lo anterior que la retórica y estética de la ciencia ficción cobra un papel tan relevante, ya que le da un soporte estable a la triangulación de estas tres dimensiones, permitiendo la confluencia de metarrelatos político-históricos y de un ejercicio memorístico vinculado con una realidad histórica específica, por lo tanto, las conclusiones que se desprenden, responden también a este vínculo con la historia y la memoria extratextual desde donde, finalmente, emana toda inspiración para la creación de las obras exploradas en este artículo.

Como primer aspecto, las novelas gráficas Zombies en La Moneda jestamos en guerra, señores!, El gran guarén: los archivos perdidos y 1959: Metahulla 2 construyen al personaje de Pinochet, tanto en su constitución fisionómica como en el trasfondo de su relato en las distintas diégesis, reutilizando los componentes asociados a su contrapunto real, lo que se evidencia en la información textual que aparece formando la caracterización de Pinochet, en los personajes que lo acompañan y en la forma en que es retratado en las ilustraciones (sobre todo en las dos primeras novelas analizadas). Todo lo anterior se sustenta en base a la carga histórica y biográfica que tienen los nombres propios de las figuras que se desarrollan en los argumentos, conformando un trasfondo que se alimenta de la memoria-historia.

En un segundo punto, como se ha podido observar en el transcurso de este trabajo, los rasgos de la ciencia ficción funcionan de pilar para los dispositivos semánticos de las obras, sin embargo, se ve reforzada por la construcción multimodal del relato y sus personajes. Esto conlleva a que el engranaje entre imagen y texto, independiente de cual concentre mayor parte del contenido de la novela, genere un efecto en el lector al mantener el pacto de ficción y posibilite una mejor comprensión de la diégesis. En definitiva, al tratarse de textos multimodales, el personaje de Pinochet es anclado a una estructuración primordialmente iconotextual, pues no se trata simplemente de narrativizar las distintas ilustraciones sino de imbricar el código verbal y visual para encuadrar la inherencia histórica que posee en sí el personaje. 
Por último, es importante agregar que ni la noción de dictadura ni de golpe de Estado están abordadas de forma directa en las novelas gráficas, de modo que todo el contenido que estas cuestiones podrían aportar a las fabulaciones, quedan traducidas en una carga simbólica a partir de los personajes de Pinochet y Allende. Son estas dos figuras las que posicionan las tensiones con el pasado dictatorial de Chile, no obstante, es el primero quien resalta, pues su construcción como personaje de ciencia ficción articula los subtextos que emergen en las novelas gráficas y que revisitan, desde la retórica del género, el proceso social, político e histórico de la dictadura junto con las consecuencias de ésta dentro de la sociedad chilena, explorando la muerte de Salvador Allende y el ascenso al poder de Pinochet en El gran guarén: los archivos perdidos y haciendo una sátira sobre el influjo permanente del dictador tanto en los medios de comunicación como en las principales figuras de la actualidad política de Chile como ocurre en Zombies en La Moneda, iestamos en guerra, señores! Inclusive, en 1959: Metahulla 2, a pesar de que se distancia al configurar al personaje como un ser afable, se comprende su rol como modulador entre la ficción y la memoria, especialmente con el cierre de la parte gráfica de la novela, en el que se hace referencia a otros mundos posibles.

\section{REFERENCIAS BIBLIOGRÁFICAS}

Álamo, F. (2006). La caracterización del personaje novelesco: perspectivas narratológicas. Signa, revista de la Asociación Española de Semiótica, 15, 189-214. Recuperado de http://www.cervantesvirtual.com/obra/la-caracterizacin-del-personaje-novelesco-perspectivas-narratolgicas-0/

Álvarez, C., Tralkan, P., Adriazola, C., Bahamondes, J., González, J., Magaña, F. y Sumonte, C. (2016). El gran guarén: Ios archivos perdidos. Santiago de Chile: Acción Cómics

Avelar, I. (1999). The Untimely Present: Postdictatorial Latin American Fiction and the Task of Mourning. Durham: Duke University Press.

De Certeau, M. (1995). Historia y psicoanálisis. Entre ciencia y ficción. México: Universidad Iberoamericana.

Eisner, W. (2017). La narración gráfica. Principios y técnicas del legendario dibujante Will Eisner. Barcelona: Norma editorial. 
Equipo ZELM (2015). Zombies en La Moneda iestamos en guerra. Señores! Santiago de Chile: Mithyca Ediciones.

Logie, I. \& Willem, B. (2016) Narrativas De La Postmemoria En Argentina y Chile: La Casa Revisitada. ALTER/NATIVAS, 5, 1-25. Recuperado de https://alternativas.osu. edu/es/issues/autumn-5-2015/essays/logie-willem.html

Muñoz, A. (2009). Realidad virtual y memorias posibles: Apuntes sobre la presencia de mundos virtuales en el cine postmoderno de ciencia-ficción. Eikasia: revista de filosofía, 24, 1-10. Recuperado de https://dialnet.unirioja.es/servlet/articulo? codigo $=3018770$

. (1993). La realidad de la ficción. Sevilla: Renacimiento.

Mussetta, M. (2016). La ficción multimodal: breve recorrido teórico y principales supuestos actuales. En C. Saleme (Ed.), De la imaginación a la representación (pp. 100-123). Bahía Blanca: Editorial de la Universidad Nacional del Sur.

Ojeda, B. (2018). La dictadura chilena en viñetas. Tebeosfera. Tercera Época, 8. Recuperado de https://www.tebeosfera.com/documentos/la_dictadura_chilena_en_vinetas.html

Ortega, F. y Dániel, N. (2018). 1959: Metahulla 2. Santiago de Chile: Planeta Cómic

Peirce, C. (1955). Logic as Semiotic: The Theory of Signs. In J. Buchler (ed.), Philosophi-cal Writings of Peirce (pp. 98-119). New York: Dover.

Richard, N. (1998). Residuos y metáforas: ensayos de crítica cultural sobre el Chile de la transición. Santiago de Chile: Editorial Cuarto Propio.

Ricoeur, P. (1996). El otro como sí mismo. México: Siglo Veintiuno editores.

Sáez, D. (2011). Tendencias, posibilidades y experiencias en E/LE del cómic como texto multimodal. En S. De Santiago Guervós, M. Seseña Gómez, J. J. Sánchez Iglesias, \& H. Bongaerts (Eds.). Del texto a la lengua: La aplicación de los textos a la enseñanza-aprendizaje del español L2-LE, 2, 769-780. Recuperado de http://www.cervantesvirtual.com/nd/ark:/59851/bmc0z950

Trujillo, G. (1990). La ciencia ficción. Literatura y conocimiento y literatura. México: Instituto de Cultura de Baja California.

White, H. (2010). Ficción histórica, historia ficcional y realidad histórica. Buenos Aires: Prometeo Libros. 